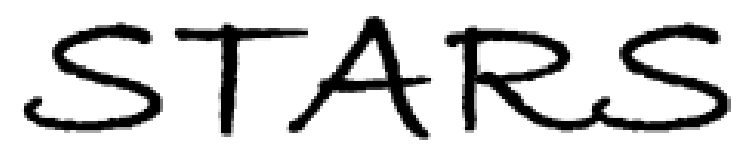

University of Central Florida

STARS

Faculty Scholarship and Creative Works

7-8-2015

\title{
The Use of Consumer-Generated Feedback in the Hotel Industry: Current Practices and Their Effects on Quality
}

\author{
Edwin Torres \\ University of Central Florida, edwin.torres@ucf.edu \\ Howard Adler \\ Carl Behnke \\ Li Miao \\ Xinran Lehto
}

Part of the Hospitality Administration and Management Commons, and the Tourism and Travel Commons

Find similar works at: https://stars.library.ucf.edu/ucfscholar

University of Central Florida Libraries http://library.ucf.edu

This Paper is brought to you for free and open access by STARS. It has been accepted for inclusion in Faculty Scholarship and Creative Works by an authorized administrator of STARS. For more information, please contact STARS@ucf.edu.

\section{Original Citation}

Torres, E.N., Adler, H., Behnke, C., Miao, L., \& Lehto, X. (2015). The use of consumer generated feedback in the hotel industry: Current practices and their effects on quality. International Journal of Hospitality and Tourism Administration, 16 (3), 224-250.

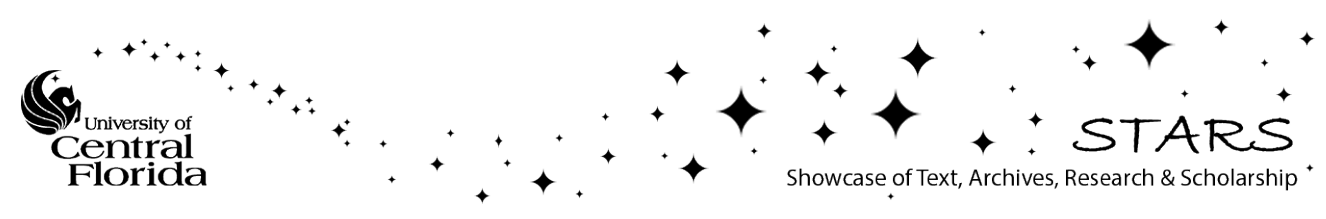




\section{The use of consumer generated feedback in the hotel industry: Current practices and their effects on quality}

Consumer-generated feedback is hard to ignore these days. Word-of-Mouth has expanded beyond a customer's immediate friends and family; and with the help of technology reaches thousands of current and prospective guests. In light of this, scholars and practitioners are exploring the subject of consumer generated feedback. Today, most of the research regarding this subject focuses on the use of consumergenerated feedback to make purchase decisions. In contrast, the present study explores the use of such information for the purposes of improving hotel operations. Throughout the course of this paper, the researchers inquire about the amount of value placed on consumer-generated feedback, the relative importance placed on positive and negative feedback, and its effects on perceived quality. Furthermore, this study inquires as to the specific uses given to consumer-generated feedback in the hotel industry. It is the researchers' contention that valuing feedback has positive effects on perceived quality. The research concludes that hotels can use consumer-generated feedback to take actions such as modifying training programs, operating procedures, as well as identifying patterns of complaint and praise.

Key Words: Consumer-generated feedback, Consumer reviews, Service quality, Hotels, Hospitality 


\section{Introduction}

Customers provide advice to each other in a variety of topics ranging from their favorite restaurant to their most trusted doctor. This informal means of communication from one consumer to another without the direct influence of a marketer often is referred to as word-of-mouth communications (WOM). More precisely, Westbrook (1987) defined word of mouth as: "informal communications directed at other consumers about the ownership, usage, or characteristics of particular goods and services and/ or their sellers" (pp. 261). WOM is of critical importance due to its potential impact in consumer purchase decisions, customer acquisition, and consequently increased revenue for organizations (Litvin, Goldsmith, \& Pan, 2008; Trusov, Bucklin, \& Pauwels, 2009). In fact, WOM has been found to have a positive effect on customer acquisition. In the past, people shared information about products and services with friends and family. Nevertheless, the advent of the internet provided yet an additional outlet where consumers could express their opinions. Although other forms of WOM are worthy of study in their own right, the present study focuses on one form of WOM: online consumer-generated feedback. Many products and services are evaluated by consumers online, yet the hospitality industry has witnessed these changes up close. It has been proposed that intangible and experiential products (such as those offered by hospitality providers) are more likely to be the subject of electronic word-of-mouth (Senecal and Nantel, 2004). With various travel sites, blogs, social media sites, and other outlets, today's empowered customer has various options in the search for information. In light of this, researchers have taken an interest in the subject (Senecal \& Nantel, 2004; Schmalegger \& Carson, 2007; O’Mahony \& Smyth, 2009; Cox, et.al, 2009; O’Connor, 2010; Kasavana, et.al., 2010; and Sparks \& Browning, 2011).

While the work of the aforementioned authors has helped advanced our knowledge of consumergenerated feedback, more research could illuminate the ways and means by which feedback is utilized by hoteliers. This study proposes that hotel General Managers can potentially use such feedback to make operational changes resulting in service quality improvements. The literature on the topic of consumergenerated feedback reveals different streams. One such stream of research focuses on how consumer 
feedback affects a prospective customer's purchase decision process (Sparks \& Browning, 2011; Williams et.al., 2010; Vermeulen \& Seegers, 2009; Pavlou \& Damoka, 2006). Another stream focuses on how hoteliers can preserve or enhance their image online (Schmallegger \& Carson, 2007; O’Connor, 2010). In spite of this, more attention is warranted as to the effects of such feedback in hotel operations. Whereas, previous research has addressed. Therefore, this study has identified the following gap in the current literature: the use of consumer-generated feedback for operational purposes. Hotels can arguably gain information from consumer-generated feedback that will help them improve the quality of the services they provide.

The source of feedback is clearly important, but so is the nature of such information. Some of this feedback is positive in nature whereas some is negative. The present research, sought to understand the relative importance placed on each of these two by hotel management. Whereas previous research has highlighted the processes of handling complaints in the hospitality industry (Dinnen \& Hassaninen, 2011), the present research shows how both positive and negative feedback is handled, the relative importance placed on each, as well as some of the actions taken following such feedback including decisions about the selection of guest amenities, training programs, policies and procedures, and other key managerial decisions. The hotel industry could benefit from understanding both negative and positive comments. Negative comments can be used systematically to correct consistent patterns of complaints through re-training, and changes in operating procedures, for instance. Positive comments can be used systematically to detect consistent patterns of customer delight and emphasize those delight factors through re-training, changes in operating procedures, and reward systems, among others.

The purpose of this study was to explore the amount of value that hotel General Managers place on consumer-generated feedback, the actions they take based on such feedback and its impact on the quality of the services they provide. Arguably, the present study can contribute to both the theory and practice of hospitality by exploring the links between the use of feedback and service quality, and 
providing best practices to hotel regarding their monitoring and action planning based on such information. In light of the current state of research, the following research objectives were proposed:

- Determine the value placed on consumer-generated feedback by hotel General Managers;

- $\quad$ Determine the relative importance placed on positive and negative feedback;

- Explore the extent to which managers use consumer-generated feedback systematically to make changes in operating procedures, train employees, create reward systems, hold employees accountable, resolve immediate guest problems, and improve the hotel's image, among others.

\section{Review of the Literature}

\section{Consumer Generated Feedback}

The topic of word-of-mouth (WOM) communications is not new in the services industries. Nevertheless, the advent of new electronic outlets for WOM is relatively a recent phenomenon. Electronic means of communication such as travel feedback sites (i.e. Trip Advisor, Yelp), social networking sites (i.e. Facebook), and blogs have allowed consumers to take their WOM to people beyond their inner circle. Electronic forms of word-of-mouth are often referred to as consumer-generated feedback. Whereas consumers have always expressed their feedback through more traditional forms of WOM such as customer feedback letters, comment cards, and in-person guest complaints; today electronic media allows consumers to generate feedback online, and thus consumer-generated feedback has gained momentum. Consumers engage in WOM for a variety of purposes. Sundaram, Mitra, and Webster (1998) proposed that four reasons for consumers to engage in positive word -of- mouth include: altruism, productinvolvement, self-enhancement, and helping the company; whereas four reasons why people engage in negative WOM include: altruism, anxiety reduction, vengeance, and advice-seeking. In addition to these motivations, Harrison-Walker (2001) proposed that affective commitment is an antecedent to WOM. Other than consumer's motivations, researchers have also studied the potential benefits to the users of 
electronic WOM. Ng, David, and Dagger (2011) proposed that some of these benefits include confidence, social, and special treatment. That study, which inquired about the services received in two industries (beauty treatment and veterinary services), also discovered that service quality can be an antecedent to WOM depending on the particular industry.

Researchers have also studied the factors that impact the strength of mouth including: closeness of the communication to the receiver, strength of the expression, amount of room for change, whether WOM is solicited or not, whether the WOM is about the receiver's main brand, how much WOM was given about a particular category, as well as age, gender and product category (East, Hammond, \& Lomax, 2008). Their study concluded that the impact of positive WOM is typically greater than the impact of negative word of mouth. Additionally, Kim (2009) proposed that business travelers, as opposed to leisure travelers, are more likely to respond to negative word of mouth.

One source of WOM which has been the subject of attention in recent years, consumer-generated feedback, is the focus of this study. Whereas WOM research explores various forms of consumer communications, research on consumer-generated feedback specializes in electronic platforms for such feedback such as TripAdvisor, Yelp, and blogs among others. One of the topics of interest within consumer-generated feedback is that of its use for purchase decisions. Research by Cox, Burgess, Sellitto, and Buutjens (2009) suggested, that consumers are more likely to utilize consumer - generated content at the information gathering stage of the purchase decision process. Pavlou and Domoka (2006) discovered that people rarely view comments beyond the first two pages in feedback sites. Sparks \& Browning (2011) studied whether or not the existence of a numerical rating impacted consumer decisions. They discovered that numerical ratings were only relevant when accompanied by verbal feedback. The use of user generated content also has been studied within various industries. Senecal and Nantel (2004) suggested that consumer-generated feedback is more important to prospective purchasers of experiential products. 
Vermeulen and Seegers (2009) explored the role of consumer-generated feedback on the purchase decision process. User reviews can increase the likelihood that a hotel will move from a universal set of choices (the whole spectrum of products) to a consideration set of choices (a smaller subset from which a decision is made) regardless of positive or negative comments. Such a relationship is more prevalent for independent hotels. In support of this, Chen (2008) argues that people use user generated content to reduce risk and avoid uncertainty. However, concerning hotel choices and making a final decision, the nature of the positive or negative comments becomes more important. Positive reviews are likely to have a correspondingly positive effect on consumer attitudes. This relationship is also more prevalent for lesser-known hotels (Vermeulen \& Seegers, 2009).

The use of consumer-generated feedback to make decisions also has financial implications. Ye, Law, and Gu (2009) developed a mathematical model to explain the impact of user generated comments on hotel sales and profitability. Accordingly, a $10 \%$ improvement in reviews led to a $4.4 \%$ increase in sales. Brian Ferguson (Executive Vice-President of Expedia) recently disclosed that according to his records "A one- point increase in a review score equates to a 9\% increase in ADR" (Lynch, 2012). Other researchers have explored the relationship of positive reviews and traffic to the business' website, in this case a restaurant (Zhang, Ye, Law, \& Li, 2011). That study confirmed that there is a positive relationship between good reviews at a third party site and traffic to a restaurant's proprietary website.

Another area of interest for researchers is that of the credibility of consumer-generated feedback. Researchers have evaluated travel websites comparing user-generated content to other sources of information in terms of their credibility and use to make decisions (Cox et.al., 2009). Other challenges associated with consumer reviews included bias, statements that are very broadly written and cause potential information overload (O’Mahony \& Smyth, 2009). Travel websites were very popular among consumers, but they may not considered to be as credible or trustworthy as other sources (Cox, et.al., 2009). Furthermore, the researchers propose that travel websites are only one of many decision making 
sources. Nevertheless, there seems to be a relationship between consumer-generated feedback and how favorable people view such feedback.

The lack of control and verification processes for the information posted makes it vulnerable to people who post false information that is positive or negative about a particular hotel. Keates (2007) proposed that there are a variety of factors that can identify a fake review. A false review typically has scores that greatly differ from other reviews. Such reviews will typically mention nearby properties as superior. Finally, false reviewers will only post information regarding one visit to one hotel; they do not have a history of posting in the website (Keates, 2007). In spite of the concerns for the veracity of the information, O'Connor (2010) suggested that very few of the comments presented today at such sites can be considered suspect. In response to this, several hotel chains or are in the process of launching their own feedback sites (Nayer, 2011).

Some research in the area of consumer generated feedback has focused on the image of the hotel. Research by Kasavana, Nusair, and Teodosic (2010) used benchmarking to demonstrate how hotels can successfully use social networking as a marketing tool. Some hotels create photo contests for guests, and encourage them to share videos and stories. Furthermore, hotels have used social networking to help guests interact with one another before a stay and create contacts to socialize during their visit (Kasavana et.al., 2010). Schmalegger and Carson (2007) discussed the challenges and opportunities for hospitality and tourism organizations that use blogs. Some of the alternatives include hiring an experienced and professional blogger and letting employees blog about their companies among others. Hotels have also enticed guests by granting vouchers and designing contests. The research of Schmalegger and Carson (2007) explored some potential uses of consumer-generated feedback. The present research provides a more detailed overview of the actions taken by hotel General Managers and their perceptions of such actions on the quality of services. 


\section{Consumer-Generated Feedback and Service Quality}

Despite the emerging literature on consumer generated feedback, more research is warranted concerning the use of such information to improve service quality and guest relations. Schmallegger \& Carson (2007) proposed that blogs and other consumer generated feedback can provide hoteliers information on how to improve their quality. Accordingly, this information can help them track the attitudes, opinions, and satisfaction of guests over the course of time. Another area of interest pertains to the actions taken by the management of a hotel following positive or negative online feedback. According to $\mathrm{Yu}(2010)$, less than $4 \%$ of the negative online reviews receive a response by a hotel manager. However, some hotels pay close attention to the feedback and are taking steps to ensure their quality. Some of the steps taken by hotel companies include designating a person as a Review Analyst or other job title, whose job duties involve analyzing consumer feedback (Yu, 2010). Some companies also use specialized software such as Review Analyst and Revinate to manage the vast amount of online content. Hanson in $\mathrm{Yu}$ (2010) stated that some managers use reviews to improve training, adjust staffing levels, and add or remove amenities. The literature on the use of consumer-generated feedback proposes that such information can be used to improve the quality of a hotel's operations. Yet, it is still unknown whether such monitoring, as well as the subsequent actions taken afterwards have a direct impact on quality. Therefore, hypothesis 1 is proposed:

Hypothesis 1: There is a positive relationship between the value hotel General Managers place on consumer-generated feedback and their perceptions of quality improvement.

In addition to exploring quality in general, the researchers also wanted to determine whether specific aspects of quality were improved as a consequence of placing more value on consumer feedback. In light of this, Hypothesis 2 was proposed:

Hypothesis 2: There is a positive relationship between the value hotel General Managers place on consumer-generated feedback and their perception of improvement in consumer feedback ratings. 
Quality has been defined in different ways. Reid and Sanders (2002) propose that quality can be viewed in terms of conformance to specifications, fitness for use, value for the price paid, support services, and psychological criteria. Service researchers have explored the concept of service quality within the framework of several service organizations. Parasuraman, et.al. (1988) defined service quality as "a form of attitude, related but not equivalent to satisfaction and results from a comparison of expectations with perceptions of performance". Nightingale (1979) suggests that quality is an evolving personal construct of values and expectations against which an individual evaluates a product or service. Seth, Deshmukh, and Vrat (2004) conducted a comprehensive search for quality models and summarized them in chronological order. Accordingly, 19 different models were identified to explain service quality. These models include: Technical and Functional Quality, GAP Model, SERVQUAL, Attribute Service Quality, Synthesized Model, Performance Only Model (SERVPERF), Ideal Value Model, Evaluated Performance and Normative Quality, IT Alignment Model, Attribute and Overall Affect, Perceived Service Quality and Satisfaction, and PCP Attribute Model.

One of the most prevalent criticisms to the current conceptualizations of service quality is that such definitions not significantly different to conceptualizations of customer satisfaction. For example Cronin and Taylor (1992) proposed: "The current operationalization of service quality confounds satisfaction and attitude" (pg. 55). In the hotel industry, various techniques have been employed to ensure service quality. Many hotels in the United States utilize formal rating systems, such as those offered by the American Automobile Association (AAA) and Forbes. Su and Sun (2007) explored the rating systems of four different countries and presented some of the similarities and differences between them. Beck and Miao (2003) studied mystery shopping as a source of information for hoteliers. Additionally, Callan (1990) explored the perceptions of service quality from travel journalists.

There are multiple additional tools that hoteliers use to measure their quality. Some of these include quality awards. For example, the Ritz Carlton received the prestigious Malcolm Baldridge Quality award (NIST, 2011). Other researchers have attempted to implement quality audits in the hotel industry 
(Luchars and Hinkin, 1996). Adebanjo, Abbas, and Mann (2010) studied benchmarking as a tool for continuous quality improvement. Hotels can also rely on their training and development programs to ensure service quality (Claver-Cortes et.al., 2007). Finally, one of the most studied service quality tools, SERVQUAL, has been the subject of much attention. This tool emphasizes five areas of service: tangibles, reliability, responsiveness, assurance, and empathy (Parasuraman et.al., 1988). Enz and Siguaw (2000) studied various hotel companies with successful quality management practices. Their study defined the success of these companies via various measures including financial results (i.e. occupancy, ADR, market share, profitability), customer-related measures (i.e. increased customer satisfaction, customer retention), improved human resource results (i.e. decreased employee turnover, increased employee satisfaction, employee involvement), and competitive measures (i.e. winning an award). This research sought to explore the perceptions of improvement of quality by General Managers by taking a broader look at the various feedback sources received by management including consumer-generated feedback, customer satisfaction scores, hotel rating systems, mystery shopping evaluations, and internal feedback.

Consumer generated feedback can be used for a variety of purposes. Accordingly, different actions can be taken following the receipt of positive and negative feedback. Some hotels have used the information to improve training, adjust staffing levels, and add or remove amenities (Yu, 2010). ClaverCortes et.al. (2007) proposed that companies that excel in service have more advanced training systems. In support of this notion, Chand and Catou (2007) discovered that training was positively correlated with service quality. Given the multiple actions that General Managers can take with regards to consumer feedback, it is pertinent to ask whether some actions are more effective than others in bringing about quality in organizations. Consequently, Hypothesis 3 and 4 were proposed.

Hypothesis 3: Hotel General Manager's systematic use of consumer-generated feedback (i.e. by changing policies and procedures, training systems, reward systems) is positively associated with quality improvement. 
Hypothesis 4: There is a positive relationship between the amount of use of positive feedback and quality improvement

Based on research the existing research and the hypotheses proposed by the authors, Figure 1 is presented.

\section{>>Insert Figure 1 Here $<<<$}

\section{Methodology}

Based on the literature review a survey was designed. Qualitative interviews were also conducted. The purpose of the interviews was twofold. First the researchers wanted to compare the results against those of the survey. Second, interviews provided additional insight as to the reasons for the choices made by General Managers in the survey. The survey was sent to hotel General Managers of hotels rated in the four or five diamond category according to the American Automobile Association (AAA). The AAA list was used for several reasons. First, it provided an extensive list of properties, more so than the Forbes / Mobil list. Second, the list assured that the survey was delivered to upscale hotels, the target of the study. Arguably, upscale hotels have to make extra efforts to ensure their image and quality are sustained, and thus the study of the feedback they receive is particularly relevant. Third, the directory provided a list of managers and reduced bias associated with the researchers choosing respondents.

The list of both four and five star properties totaled 1,102 hotels. The researchers called each of these hotels and attempted to obtain the name of the General Manager. Most hotels provided the information. However, some hotels did not have a General Manager at the current time or were unwilling to provide the information. Consequently, a total of approximately 1,000 surveys were sent. The survey was mailed through the United States Postal Service. A total of 140 surveys were returned for a response rate of $14 \%$. After completing the survey, General Managers were encouraged to submit their business cards if they were willing to participate in qualitative interviews. From these business cards, General Managers were contacted and subsequently interviewed. A total of twelve participants were part of the qualitative study. 
The survey was sent via the Postal service with a postage paid envelope for its return. For the qualitative portion of the research semi-structured interviews were conducted. In order to facilitate the process, an interview protocol was developed. After the survey was received and the data analyzed, the researchers wanted to explore some of the topics in further depth and uncover the reasons for various practices. The instrument contained questions regarding management practices associated with compiling, reporting, and taking action in relation to consumer feedback. After interviewing the respondents, the researchers transcribed the interviews. A codebook was developed based on the literature, the gaps in the survey, and the themes identified during the interview process. The researchers then performed content analysis of the letters by assigning the appropriate codes and counting the frequencies and percentages of occurrence.

Regression analysis was used for the study. The assumptions about multiple regression were also tested. Unless otherwise stated, none of the regression assumptions were violated. An analysis of reliability was conducted (internal consistency reliability) to measure the extent to which various operational measures accurately measure their desired target. An alpha of .05 was pre-set as an acceptable level of significance. A second method statistical tool used during this study was correlation analysis. SPSS was used as the statistical analysis software. The statistical consulting service at Purdue University was utilized to ensure proper use of statistical procedures.

\section{Definitions and Measures}

For the purpose of the present research, value placed on feedback is given the following operational definition:

Value Placed on Consumer-Generated Feedback: The degree of importance that General Managers give to feedback generated by consumers (including travel sites, travel booking sites, social networking sites, and other forms in which consumers can express their opinions about a hotel's service). 
Quality Improvement: The attainment of better and or higher quality evaluations by hotel consumers, expert raters, and internal parties. The perception of improvement relates to the improvement of these categories, as related by hotel General Managers.

In order to obtain responses from General Managers, a survey instrument was designed (see Appendix 1). In order to test Hypothesis 1 (There is a positive relationship between the value hotel General Managers place on consumer feedback and their perceptions of quality improvement), the value hotel management placed on consumer feedback was measured using a seven - item scale. The scale contained many of the different types of feedback used in the industry and studied in academia. Some of these include reviews on websites such as trip advisor, consumer blogs, and social networking among others. Each item was measured on a five point Likert- type scale. The internal consistency reliability of this scale was confirmed with Crombach's Alpha $($ Alpha $=.793)$. The dependent was the perceptions of quality improvement. For the purpose of measuring this scale, six items were utilized. Some of these items are used in the industry and studied in academia. They include customer satisfaction, ratings by professional raters (i.e. AAA, Forbes, mystery shoppers), and internal evaluations among others. See question eight in Appendix A for details. The internal consistency reliability was determined using Chrombach's Alpha (Alpha $=.804)$. Therefore, the reliability of the scale was established.

In addition to exploring quality in general, the researchers also wanted to determine whether specific aspects of quality were improved as a consequence of placing more value on consumer feedback. In light of this, Hypothesis 2 was proposed (There is a positive relationship between the value hotel General Managers place on consumer feedback and their perception of improvement in consumer feedback ratings). Accordingly, the researchers performed regression analysis on several of the quality variables. The relationship between the value placed on customer feedback (composed of the items in question four, Appendix A) and the perception of improvement in in consumer generated feedback (specifically, question 8-d in Appendix A) was of special interest. 
Consumer generated feedback can be used for a variety of purposes. Accordingly, different actions can be taken following the receipt of positive and negative feedback. For hypothesis three (Hotel General Manager's systematic use of consumer feedback is positively associated with quality improvement.), a four item scale was developed and titled "systematic used of feedback". The questionnaire provided General Managers with a series of practices that emerged from their use of consumer feedback (Question 5 in Appendix A). The practices associated with a 'systematic' use of feedback where those that were long-term oriented. The items included were 5-c (make changes in operating procedures), 5-e (identify patterns of complaints), 5-f (identify patterns of praise), and 5g (to train or re-train employees). Internal consistency reliability was obtained by using Crombach's Alpha $($ Alpha $=.657)$. Hypothesis 4 explored whether taking time to explore positive feedback had positive effects on quality. For the use of positive feedback, the researchers developed question six in the questionnaire. Quality variables are assessed with question number eight (see Appendix A for details).

\section{Results}

Quantitative Results- Descriptive Data

Descriptive statistics were obtained for the survey questions. These helped the researchers obtain an overall picture of the research. They also provided a closer view at managers' perceptions and usage of consumer generated feedback. General Managers were asked whether they or someone within their organizations monitored customer feedback. All respondents (100\%) answered "yes" to this question. General Managers also were asked to report on the title (s) of the people that monitor feedback in their organizations. A list of job titles and the frequency of response are listed in Table 1:

\section{>>Insert Table $1<<<$}


General Managers were asked about how frequently someone in their organizations monitors consumer-generated feedback. A total of 124 General Managers (approximately 90\%) stated that they reviewed such feedback on a daily basis. Some of them added that they receive alerts in real time. A smaller number of managers stated that they monitor feedback weekly ( $8 \%)$ or monthly $(2 \%)$.

Managers were asked about the amount of value they place on various sources of consumer feedback. The options were organized in a Likert - type scale ranging from "no value" (1) to "extremely valuable" (5). Results suggest that General Managers place greater value on personal forms of feedback rather than electronic ones. Within the realm of electronic word of mouth, and specifically consumer generated feedback, reviews on travel websites such as Tripadvisor were most valued by managers (mean = 4.25); blogs received the least value (3.5). Table 2 summarizes the mean and standard deviation for each one of the items:

\section{>> Insert Table $2<<$}

General Managers were asked about the various forms of consumer generated feedback they used to make changes in their current practices and operating systems. Respondents were asked to select an answer in a 5 point Likert - type scale ranging from "strongly disagree" (1) to "strongly agree" (5).

Overall, most practices received very high scores by General Managers. The highest score was came from the item "to identify patterns of complaints" (mean =4.73). The lowest score came from the item "to make changes in operating procedures" $($ mean $=4.36)$. Table 3 summarizes the means and standard deviations of the various operational practices related to guest feedback.

\section{>>Insert Table $3<<$}

The researchers examined whether hotel General managers pay more attention to positive or negative feedback. In the survey, managers were posed a question to rate their time in evaluating feedback from "spend significantly more time addressing negative feedback" to "spend significantly more 
time addressing positive feedback. The most negative answer was coded "-2" and the most positive was coded " 2 ". The position of neutral or spending equal amount was labeled "O". The mean response from General Managers was -.74, thus indicating that they spend slightly more time in negative feedback.

A hotel can use different criteria to measure its quality. The study considered feedback given by experts such as the formalized rating system of AAA and Forbes, feedback given by consumers especially in the form of electronic WOM and feedback provided internally such as that given by internal stakeholders ranging from front-line employees to corporate executives. The study specifically attempted to examine whether greater value placed on consumer-generated feedback helped a hotel improve its quality with several criteria. Responses ranged from "taken a step back" to "highly improved". For each one of these responses, specific criteria were established. For example, a "highly improved" in customer satisfaction implies an increase of $7 \%$ or more in this criteria. The item in which managers reported the highest improvement was in "customer satisfaction scores", they reported the least improvement in their Forbes evaluations. The full results are summarized in Table 4.

\section{>>Insert Table $4<<$}

Quantitative Results - Test of hypotheses, regressions, ANOVA, and correlations

The first hypothesis was proposed with the intention of determining whether a relationship existed between the amount of value hotel General Managers placed on consumer-generated feedback and their perceptions of quality improvement. Simple linear regression was utilized to measure the relationship among the variables. Results demonstrate that there is a significant positive relationship between the amount of value hotel General Managers place on consumer-generated feedback and their perceptions of quality improvement. $(\mathrm{F}=3.84, \mathrm{P}-\mathrm{V}$ alue $=.052, \mathrm{r}$-square $=.029)$. In light of these findings, Hypothesis one is supported. Consequently, the more value General Managers place on consumer feedback, the most likely they are to improve their perceptions of quality. 
The second hypothesis sought to understand whether there was a positive relationship between the value placed on consumer feedback and improvement in specifically one category: perceived consumer feedback ratings. The results do confirm that there is a significant relationship among these two variables $(\mathrm{F}=14.47, \mathrm{P}-$ Value $=.00)$. Consequently the more attention General Managers place on consumergenerated feedback, the more likely they are to improve their consumer generated rankings, as reported by them.

In addition to knowing whether the amount of value placed on consumer-generated feedback has an impact on perceptions of quality and performance, the researchers also sought to understand whether specific actions performed by managers after reviewing online feedback had any impact on several outcome variables (hypothesis 3). Simple regression was utilized to determine whether a significant relationship existed between the variables. Such a statistical technique was considered most appropriate, as two variables (one independent and one dependent) were tested on their statistical significance. The results were not significant $(\mathrm{F}=1.17, \mathrm{P}-$ Value $=.282, \mathrm{R}$-square $=.009)$. Therefore we fail to reject Ho. At the $95 \%$ confidence level, we cannot state that there is a significant relationship between perceptions of quality improvement and the systematic use of consumer-generated feedback.

The study explored whether managers pay more attention to positive or negative consumer-generated feedback. Descriptive statistics show that managers tend to pay more attention to negative feedback. Following this, the researchers inquired whether those managers that pay more attention to positive feedback have better perceived quality in their hotels (hypothesis 4). Regression analysis was conducted and the results indicate a statistically significant relationship between the two variables $(\mathrm{F}=14.89$, $\mathrm{P}$ Value $=.00$ ). Consequently, more time spent in monitoring positive feedback is positively related to improvement in perceived quality.

The researchers attempted to discover whether any demographic items related to the hotel played a role in terms of the amount of value hotel General Managers place on consumer feedback. More 
specifically, the researchers explored whether the size of a hotel had an impact in the value placed on consumer feedback. Analysis of Variance (ANOVA) was conducted for these purposes. The results show that there is a significant difference in the amount of value placed on feedback based on the number of hotel rooms $(\mathrm{F}=3.2, \mathrm{P}-$ Value $=.00)$. Post-hoc tests were generated and descriptive statistics were drawn using SPSS. Based on this, smaller hotels seemingly pay more attention to consumer feedback.

A correlation matrix was generated for the questions concerning the use of consumer feedback for operations purposes. This matrix contained those items that were considered "systematic" due to their long-term orientation. The correlation matrix below shows some moderately positive correlations. Of particular interest is the correlation between item $5 \mathrm{c}$ (using feedback to make changes in operating procedures) and item 5 e (identifying patterns of complaints). Another moderately positive correlation exists between items $5 \mathrm{~g}$ (using feedback to train or re-train employees) and $5 \mathrm{f}$ (to identify patterns of praise). Table 5 presents a correlation matrix of the operational practices resulting from consumer feedback.

\section{$>$ Insert Table $5<<$}

\section{Qualitative Interview Results}

A total of twelve General Managers were interviewed. Two of these Managers were interviewed in the initial stages of the project. This aided in the creation of the survey instrument. After the survey data was collected, ten additional Managers were interviewed. The purpose of these interviews was to compare the information to that of the questionnaire and dig deeper into the reasons into the reasons for the survey answers. After the interviews were conducted, they were transcribed by the researchers. The codebook was used to code the questions in which rich information was found. Content analysis was performed on this letters using the codebook. The answers to select questions in the interview protocol follow. 
- How often do you monitor consumer generated feedback (i.e. trip advisor, social networking, etc?

All the respondents $(100 \%)$ stated that they monitor consumer-generated feedback on a daily basis. This is consistent with the survey results, in which $90 \%$ of respondents indicated that they monitor feedback on a daily basis.

- How is this feedback (i.e. consumer-generated feedback) reviewed? Do you make use of software to review this?

Today, several tools exist to help General Managers review consumer-generated feedback. One such tool is provided by a third service provider called "Revinate" and another one is "Review Analyst". Such tools help compile online consumer feedback from several sources including Trip Advisor, online travel agencies, and social networking. A total of $4(33 \%)$ of the interviewees currently use this service to help monitor feedback. The rest of them perform this task manually.

- What happens to the information once you collect the feedback? What actions (if any) are taken?

General Managers use the feedback (i.e. consumer-generated feedback) to take a variety of actions. Some of the most frequently mentioned actions include responding to former guests and reporting (or alternatively sharing) the information with other managers within the hotel. Some of the least frequently mentioned actions included encouraging posting and determining future capital improvements and renovations for the hotel. Table 6 summarizes the responses of hotel General Managers to this particular question:

\section{>> Insert Table $6<<<$}

- Do you spend more time on positive or negative consumer-generated feedback? Why?

Most General Managers spend more time monitoring negative consumer-generated feedback. Only four respondents (33\%) stated they spend equal amount of time in both. The top two reasons why General Managers spend more time monitoring negative feedback include service recovery strategies (33\%) and 
working to prevent future problems (33\%). According to the General Managers, both of these practices tend to take more time than those associated with positive feedback.

\section{Discussion and Conclusion}

The survey instrument revealed that $100 \%$ of all hotels monitor consumer-generated feedback feedback. The qualitative interviews support this finding. In previous literature, O’Connor (2010) expressed that many hotels are actively managing their image online. Given the fact that consumer generated feedback online is a phenomenon of the past few years, this finding is especially important. However, the person who monitors such feedback varies from one hotel to another. A total of $41 \%$ of all General Managers surveyed stated that they personally monitor consumer-generated. During the interview process, the researchers discovered that $44 \%$ of respondents reviewed online feedback themselves. Therefore, the findings of the survey and interviews are consistent. As far as to the value placed on feedback, most General Managers value consumer feedback, though most of them have a preference towards traditional forms of consumer feedback (i.e. in-person complaints, letters from former guests), as opposed to electronic feedback. While such forms of feedback are very important, online consumer feedback can potentially have more of an impact in a hotel, due to its widespread availability. Trusov, et al. (2009) suggested that electronic WOM can be more powerful than traditional marketing media. Furthermore, Dinnen and Hassanien (2011) proposed that management should encourage complaints and feedback. In light of this, it is critical to spend time reviewing consumer-generated and making adjustments to the service strategy based on the information collected.

One of the questions the researchers attempted to answer during the survey, concerned the actions taken by General Managers given consumer generated feedback. A list of items was given to General Managers. Some of the preferred actions by hotel general managers included identifying complaint patterns and resolving the problem at hand. Rewarding managers and employees was an important action according to those surveyed. Some of the less frequent actions included changing operating procedures 
and changing training and development. In order to obtain more detailed information as to the practices General Managers adopt given consumer-generated feedback, the researchers inquired on this aspect during the qualitative interviews. The content analysis of the interviews revealed that General Managers are more prone to take the following actions: respond to comments, create reports for internal discussions within the management team, recognizing and rewarding their employees for positive comments. Some other actions that received less attention included using the information for capital improvements, coaching and counseling of employees, and to encourage guest to post positive comments. These are consistent with the survey results. This is especially critical given the importance of feedback to make decisions (Sparks \& Browning, 2011; Vermeulen \& Seegers, 2009), as well as the financial impact of such feedback (Ye, et al, 2011).

All of these actions can potentially engender positive results for hotels. Responding to comments shows prospective guests that the hotel cares about consumer-generated feedback and is willing to resolve their problems. Creating reports and holding discussions amongst the management team can aid in identifying patterns and generating solutions to common guest problems. Recognizing employees through various reward programs can ensure that positive patterns of feedback perpetuate. Encouraging guest comments could help increase the number of positive comments online and improve the hotel's reputation. Using the information for capital improvements ensures that owners are spending money wisely in amenities that are important to the guest. While the existing literature on consumer-generated feedback discusses the importance of the information on making purchase decisions and improving the hotel's image, it does not highlight the actions taken by management given such feedback. The results of the present study highlight that General Managers take a variety of actions given some feedback, though some actions are more likely than others.

The quantitative results of the present research demonstrate that there is a positive relationship between the amount of value placed on consumer-generated feedback and perceptions of quality improvement. Therefore, General Managers who wish to improve service quality must make a 
commitment to monitoring, valuing and taking action based on consumer feedback. This will also enable them to receive better consumer ratings, as revealed in the second hypothesis. The present research also revealed that a greater emphasis placed on positive feedback can bring about better perceptions of service quality. This is consistent with research on customer delight (Torres \& Kline, 2013). Whereas negative feedback can aid in the process of service recovery, examining positive feedback can aid hoteliers in perpetuating the actions and continuing the amenities that truly delight the guest.

Although, General Managers use the information and take some actions, the study suggests that some of the actions are probably insufficient to initiate lasting improvements in service. In addition, many organizations are concerned about the image of their hotels online and rightfully so. Nevertheless, in the process of worrying about poor public relations, managers have overlooked perhaps one of the most important advances in hospitality: the widespread availability of consumer-generated feedback. Never in the history of the hotel industry have General Managers had the amount of readily available consumer feedback as today. While this presents the challenge of public relations, it also poses a great opportunity for hotels. Hotel General Managers can gain tremendous knowledge and insight into the thoughts and feelings of their guests. This information can then be used to take appropriate action to continuously improve customer service.

The present research revealed another great area of opportunity for hoteliers. Most General Managers spend more time reviewing negative feedback, as opposed to positive feedback. This is understandable, given the need for problem resolution and image management. Furthermore, some General Managers indicated that they have to spend more time doing research concerning breakdowns in the service chain. They also expressed during the interviews, that service recovery strategies can take more time. A positive comment could give an image of "no news"; whereas a negative comment typically represents a deviation in the norm, therefore is typically more salient. Indeed, General Managers should continue to monitor negative consumer-generated feedback and improve on the areas of opportunity. 
Despite the seemingly uneventful nature of positive consumer-generated feedback, General Managers could learn from such comments. Whereas negative comments tell General Managers what not to do wrong, they do not reveal what needs to go right. Positive comments, on the other hand, reveal what that pleases or potentially delights the guests. Furthermore, the present research revealed a positive association between spending time on positive consumer-generated feedback and improvement in quality variables. In fact, studies in academia have looked at patterns of positive comments online (Magnini, Crottz,\& Zehrer, 2011). Positive comments can help General Managers identify patterns of praise and perpetuate the actions that caused them, thus improving quality in the long-term. The researchers propose that General Managers ought to spend time monitoring both positive and negative consumer-generated feedback. However, the study demonstrates that not enough attention is placed on positive consumer feedback. By valuing positive comments, managers can identify what delights the guest and be better equipped to provide it.

A series of hotel demographics were tested against some of the relevant variables of study. The size of the hotel was discovered as a significant positive impact on the value placed on consumergenerated feedback. Consequently, General Managers in smaller hotels (i.e. those under 100 rooms), are more likely to value such information. Vermeulen and Seegers (2009) suggested that consumer-generated feedback can be more critical for smaller hotels, and for those without a brand affiliation. Today hotel General Managers receive plenty of consumer feedback. The present study suggests that they are paying attention to such feedback. Furthermore, the researchers propose that this feedback can be used to improve service quality. In order to sustain and improve service quality in a hotel, General Managers will do well to review not only negative, but also positive feedback. General Managers can also identify patterns of praise and complaint, modify their training programs, and reward employees for positive actions among others. In this way the hotel industry can ensure that attention is paid to this feedback and that quality is improved as a result. 
Throughout the course of the present study, the researchers have highlighted the importance of valuing and monitoring consumer generated feedback. Nevertheless, monitoring should not be the end purpose of this process. Industry leaders cannot passively track their position and comments on TripAdvisor and similar sites. If General Managers desire to improve their scores, they must take action by developing a comprehensive strategy. Such strategy can ensure that patterns are identified, information is disseminated within the organization, operating procedures and training programs are constantly updated given consumer comments, employees are rewarded, and capital improvements are made in amenities that please the guest. Today, managers spend countless hours trying to take actions and enact programs that will help keep guests happy. However, unless such actions and programs are grounded in what guests truly desire; management's efforts can go in vain. In the present time, consumers are speaking and empowered by technology their voices are more powerful than ever. The question remains, will management take the actions necessary to ensure their voices are heard?

\section{References}

Adebanjo, D., Abbas, A., \& Mann, R. (2009). An investigation of the adoption and implementation of benchmarking. International Journal of Operations \& Production Management, 30(11), 11401169.

Beck, J., \& Miao, L. (2003). Mystery shopping in lodging properties as a measurement of service quality. Journal of Quality Assurance in Hospitality and Tourism, 4(1/2), 1-21.

Callan, R. (1990). Hotel award schemes as a measurement of service quality - An assessment by travel industry journalists as surrogate consumers. Hospitality Management, 9(1), 45-58.

Chand, M., \& Catou, A. (2007). The impact of HRM practices on organizational performance in the Indian hotel industry. Employee Relations, 29(6), 576-594.

Chen, Y. (2008). Herd behavior in purchasing online. Computers in Human Behavior, 24, 1977-1992. 
Claver-Cortes, E., Pereira-Moliner, J., Tari, J., \& Molina-Azorin, J. (2007). TQM, managerial factors, and performance in the Spanish hotel industry. Industrial Management and Data Systems, 28(2), 228-244.

Cox, C., Burgess, S., Sellito, C., \& Buultjens, J. (2009). The role of user-generated content in tourists' travel planning behavior. Journal of Hospitality Marketing \& Management, 18, 746-764.

Cronin, J., Taylor, S. (1992). Measuring service quality: A reexamination and extension. Journal of Marketing, 56(3), 55-68.

Dinnen, R., \& Hassanien, A. (2011). Handing customer complaints in the hospitality industry. International Journal of Customer Relationship Marketing and Management, 2 (1), 69-91.

East, R., Hammond, K., \& Lomax, W. (2008). Measuring the impact of positive and negative word of mouth on brand purchase probability. International Journal of Research in Marketing, 25, 215224.

Enz, C., \& Siguaw, J., 2000. Best practices in service quality. Cornell Hospitality Quarterly, 41(5), 2029.

Harrison-Walker, L. (2001). The measurement of word-of-mouth communication and an investigation of service quality and customer commitment as potential antecedents. Journal of Service Research, $4(1), 60-75$.

Jeong, E., \& Jang, S. (2011). Restaurant experiences triggering positive electronic word-of-mouth (eWOM) motivations. International Journal of Hospitality Management, 30, 356-366.

Kasavana, M., Nusair, K., \& Teodosic, K. (2010). Online social networking: Redefining the human web. Journal of Hospitality and Tourism Technology, 1(1), 68-82.

Keates, N. (2007, June 1). Deconstructing TripAdvisor. Wall Street Journal, p. 4.

Kim, Y. (2009). Business vs. leisure travelers: Their responses to negative word-of-mouth. The Journal of the American Academy of Business, 15(1), 70-76.

Litvin, S., Goldsmith, R., \& Pan, B. (2008). Electronic word-of-mouth in hospitality and tourism management. Tourism Management, 29 (3), 458-468. 
Luchars, J. Y., \& Hinkin, T. R., 1996. The service-quality audit: A hotel case study. Cornell Hospitality Quarterly, 37(1), 34-41.

Lynch, J. (2012, January 10). Online review reputation management trends for hotels in 2012. Sabre Hospitality Solutions. Retrieved on February 6, 2012 from http://www.sabrehospitality.com/blog

Nayer, M. (2011, November 23). How far will the hotel industry take customer reviews? 4Hoteliers. Retrieved on February 2, 2012, from http://4hoteliers.com/4hotes_fshw.php?mwi=6459

Ng, S., David, M., \& Dagger, T. (2011). Generating positive word-of-mouth in the service experience. Managing Service Quality 21(2), 133-151.

NIST., n.d. Retrieved March 26, 2011 from http://www.quality.nist.gov/Ritz_Carlton_Hotel_Co.htm

O’Connor, P. (2010). Managing a hotel's image on TripAdvisor. Journal of Hospitality Marketing \& Management, 19, 754-772.

O’Mahony, M., Smyth, B. (2010). A classification-based reviewer recommender. Knowledge-Based Systems, 23 (4), 323-329.

Parasuraman, A., Zeithaml, V., \& Berry, L. L., (1988). SERVQUAL: A multiple-item scale for measuring consumer perceptions of service quality. Journal of Retailing, 64(1), 12-40.

Pavlou, P. A., \& Dimoka, A. (2006). The nature and role of feedback text comments in online marketplaces: Implications for trust building, price premiums, and seller differentiation. Information Systems Research, 17(4), 392-414.

Reid, R. D., \& Sanders, N. R., (2002). Operations management. New York: John Wiley \& Sons.

Schmallegger, D., \& Carson, D. (2007). Blogs in tourism: Changing approaches to information exchange. Journal of Vacation Marketing, 14(2), 99-110.

Senecal, S., \& Nantel, J. (2004). The influence of online product recommendations on consumers' online choices. Journal of Retailing, 80, 159-169.

Seth, N., Deshmukh, S., Vrat, P. (2004). Service quality models: A review. The International Journal of Quality and Reliability Management, 22(8/9), 913-949. 
Sparks, B. A., \& Browning, V. (2011). The impact of online reviews on hotel booking intentions and perception of trust. Tourism Management.

Su, C. S., \& Sun, L. H. (2007). Taiwan's hotel rating system: A service quality perspective. Cornell Hotel and Restaurant Administration Quarterly, 48(4), 392-358.

Sundaram, D., Mitra, K., \& Webster, C. (1998). Word-of-mouth communications: A motivational analysis. Advances in Consumer Research, 25, 527-531.

Torres, E., \& Kline, S. (2013). From customer satisfaction to customer delight: Creating a new standard of service for the hotel industry. International Journal of Contemporary Hospitality Management, $25(5)$.

Trusov, M., Bucklin, R., \& Pauwels, K. (2009). Effects of word-of-mouth versus traditional marketing: Findings from an internet social media site. Journal of Marketing, 73, 90-102.

Vermeulen, I. E., \& Seegers, D. (2009). Tried and tested: The impact of online hotel reviews on consumer consideration. Tourism Management, 30, 123-127.

Westbrook, R. (1987). Consumption-based affective responses and post-purchase processes. Journal of Marketing Research, 24 (3), 258-270.

Williams, R., Van der Wiele, T., Van Iwaarden, J. , \& Eldridge, S. (2010). The importance of usergenerated content: The case of hotels. The TQM Journal, 22(2), 117-128.

Ye, Q., Law, R., \& Gu, B. (2009). The impact of online user reviews on hotel room sales. International Journal of Hospitality Management, 28, 180-182.

Yu, R. (2010, March 23). Hotel managers monitor online critiques to improve service. USA Today. Retrieved February 6, 2012 from http://www.usatoday.com

Zhang, Z., Ye, Q., Law, R., \& Li, Y. (2011). The impact of e-word-of-mouth on the online popularity of restaurants: A comparison of consumer reviews and editor reviews. International Journal of Hospitality Management, 29(4), 694-700. 
>> Insert Appendix A Here $\ll<<$ 